ISSN 1981-416X

Licenciado sob uma Licença Creative Commons

\title{
Relação público-privado na educação: produção acadêmica sobre o Instituto Ayrton Senna (2002-2015)
}

\section{Public-Private relation in education: Academic production in Brazil on the Ayrton Senna Institute (2002-2015)}

\section{Fernando Xavier Silva, Marcia Aparecida Jacomini*}

\section{Resumo}

Neste artigo são apresentadas conclusões de revisão bibliográfica sistemática de produções acadêmicas sobre a atuação do Instituto Ayrton Senna (IAS) na educação pública, com base na análise de teses, dissertações e artigos publicados no período de 2002 a 2015. O objetivo da pesquisa foi identificar características e contribuições desses trabaIhos, com foco na análise de suas conclusões. O conjunto de trabalhos analisados foi coletado em repositórios e bancos de teses e dissertações de instituições de ensino superior, a partir dos descritores Instituto Ayrton Senna, Fundação Ayrton Senna e IAS. Foram selecionados 64 trabalhos (24 dissertações, seis teses e 34 artigos). Alguns autores das produções analisadas consideraram as parcerias entre o IAS e os municípios positivas, porém, a maior parte dos autores as considerou negativas, porque inseriram valores mercadológicos na 
escola pública e transformaram o diretor em gerente-gestor, responsável pelos resultados educacionais da escola em que atua.

Palavras-chave: Revisão sistemática bibliográfica. Instituto Ayrton Senna. Parcerias público-privadas.

\section{Abstract}

This article presents conclusions of a systematic bibliographic review of academic productions about the performance of the Ayrton Senna Institute (ASI) in public education, based on the analysis of theses, dissertations, and articles published in the period from 2002 to 2015. The objective of the research was to identify the characteristics and contributions of those academic productions, with a focus on the analysis of its conclusions. The analyzed set of works was collected in repositories and databases of theses and dissertations from universities based on the descriptors "Ayrton Senna Institute", "Ayrton Senna Foundation "and "IAS". The result of this search was a set of 64 selected works, with 24 dissertations, 6 theses, and 34 papers. Some authors of the analyzed productions considered the relation between the IAS and the municipalities positive; however, most authors considered the partnerships negative, because they inserted market values in the public school and transformed the headmaster into a manager, responsible for the educational results of the school in which he works.

Keywords: Systematic literature review. Ayrton Senna Institute. Public-private relations.

\section{Introdução}

A introdução do ideário neoliberal no Brasil nos anos de 1990 teve importantes repercussões nas políticas públicas educacionais, especialmente pela abertura a parcerias entre o setor público e o privado, advinda da Reforma do Estado (BRASIL, 1995). A proposta de serviços públicos como educação e saúde serem ofertados em parceria com o setor 
privado, amparada no discurso de melhorar a qualidade da educação pública, foi introduzida por meio de parcerias de estados e municípios com Organizações não Governamentais (ONGs).

Ancorado na ideologia de que o privado é mais eficiente que o público, um ethos empresarial representando a busca de eficiência, eficácia e produtividade, adentrou o espaço escolar em diversos países latino-americanos e reforçou a lógica da competitividade com base em um novo gerencialismo que visa à descentralização, às avaliações externas como medida de qualidade, à padronização de currículos e formações continuadas centralizadas (CANDAU, 2002).

As parcerias do Estado com o terceiro setor no provimento de serviços sociais encontram respaldo no ideário da terceira via, que defende a integração das ações do Estado com as da iniciativa privada como forma de superação da crise do Welfare State. De acordo com análises de Peroni e Adrião (2008), os teóricos da terceira via propõem um plano amplo de reformas do Estado, sendo uma delas as parcerias com o chamado terceiro setor de forma a responsabilizar instituições sem fins lucrativos pela realização de políticas sociais em cooperação com o Estado.

Com base no ideário de serviços públicos de responsabilidade não exclusiva do Estado, algumas ONGs passaram a atuar na educação pública, entre elas o Instituto Ayrton Senna (IAS) que, entre 1994-2010, período de maior envolvimento, desenvolveu projetos e programas em 1.372 municípios dos 26 estados. A partir de 2011 a atuação do IAS decaiu principalmente com secretarias municipais de educação, embora ainda mantenha parcerias.

Várias pesquisas foram realizadas sobre o papel do IAS na educação, com a finalidade de conhecer, analisar e avaliar as parcerias e a atuação do Instituto para saber em que medida os objetivos dos programas e projetos implementados foram realizados. Tendo em vista a importância de se conhecer a produção acadêmica sobre determinada temática, como forma de saber quais questões demandam mais estudos e que lacunas das pesquisas anteriores devem ser preenchidas, foi realizado um estudo que 
se inscreve como pesquisa de revisão bibliográfica sistematizada, conforme Ferreira (2009) e França, Matta e Alves (2012).

Os estudos de revisão vêm ganhando terreno nas pesquisas educacionais desde os anos 1980. Esses estudos pretendem partir da produção acadêmica já realizada para sintetizar ou mapear assuntos, temas, resultados, procedimentos, tipos de análise e encontrar lacunas e tendências. Vosgerau e Romanowski (2014) consideram que os estudos de revisão sistemática da produção científica e acadêmica são importantes por identificarem fragilidades sobre o conhecimento acumulado numa determinada área, o grau de diálogo entre as pesquisas, a duplicidade de estudos, racionalizando a produção científica de modo a auxiliar políticas de fomento à pesquisa e de dinamização dos trabalhos dos centros de pesquisa.

Há diversos tipos de pesquisa que buscam sínteses e mapeamentos de produções acadêmicas, no entanto, é preciso diferenciar os diversos modelos e seus métodos específicos. Pontuando as características de cada tipo, Vosgerau e Romanowski (2014, p. 3) observam que muitas vezes os autores usam nomes diferentes para tipos de estudos parecidos, assinalam também que é possível separar os tipos de revisão em dois grupos: "as revisões que mapeiam e as revisões que avaliam e sintetizam".

As que mapeiam correspondem às pesquisas de levantamento bibliográfico, revisão da literatura, revisão bibliográfica, estado da arte, revisão narrativa e estudo bibliométrico. Tais tipos de pesquisa são muito dispares em suas ferramentas metodológicas e referenciais teóricos e todos têm em comum um ponto principal: "a finalidade central de levantar indicadores que fornecem caminhos ou referências teóricas para novas pesquisas" (VOSGERAU; ROMANOWSKI, 2014, p. 175).

No segundo grupo, o que corresponde aos tipos de pesquisas de revisão que avaliam e sintetizam, estão a revisão sistemática, a revisão integrativa, a metassíntese qualitativa, a meta-análise, a metassumarização e a síntese de evidências qualitativas, cujo denominador comum é "identificar as condições em que determinadas evidências ocorrem e a possibilidade de identificação de padrões de ocorrência" (VOSGERAU; ROMANOWSKI, 2014, p. 175). Estes estudos caracterizam-se pelo rigor 
na coleta dos dados e no estabelecimento de critérios de inclusão e exclusão de dados, sistematização dos resultados para contemplar a questão central do estudo. Essas pesquisas focam nos resultados dos trabalhos científicos e buscam relações entre eles no acumulado da área, de forma a encontrar lacunas, similaridades e incongruências. Seus objetos de estudos podem ser tanto estudos qualitativos quanto quantitativos.

A presente pesquisa pode ser classificada como uma revisão bibliográfica sistematizada (FERREIRA, 2009; FRANÇA), correspondendo ao segundo grupo de pesquisas de revisão, o que avalia e sintetiza. É preciso ressaltar que não são bem claros os limites entre alguns tipos de pesquisas de revisão, por isso, alguns estudos autodeclarados revisões de literatura têm seus objetivos e métodos muito semelhantes aos que serão adotados neste trabalho.

Optou-se pela leitura integral da produção acadêmica sobre o IAS. Entende-se que para realizar um levantamento das informações necessárias quanto aos posicionamentos dos pesquisadores em relação às atuações do IAS, às concepções de Estado, educação e políticas públicas, seria indispensável a leitura integral dos trabalhos, o que também possibilitou a busca dos dados referentes à caracterização geral dos estudos, assim como suas contribuições. Dessa forma, "os resultados qualitativos e as condições de aquisição desses resultados necessitam ser agrupados e reagrupados de forma interpretativa, por semelhanças, para que possam responder à questão central de pesquisa proposta" (VOSGERAU; ROMANOWSKI, 2014, p. 179).

Feito o levantamento e a coleta da produção acadêmica sobre o IAS, os trabalhos encontrados passaram por triagem para seleção daqueles que se enquadravam no critério estabelecido pela pesquisa, ser tese de doutorado, dissertação de mestrado ou artigo acadêmico. Estabelecido o corpus da pesquisa - seis teses, 24 dissertações e 34 artigos - partiu-se para a leitura integral dos trabalhos com foco nas conclusões e resultados. Após a leitura e o levantamento das informações realizou-se a análise procurando responder às seguintes questões: quais foram os resultados e 
conclusões das pesquisas em questão? Quais as similaridades e diferenças entre as conclusões e resultados desses estudos?

Para a coleta dos trabalhos sobre o IAS foram utilizadas as seguintes palavras-chave: Instituto Ayrton Senna, Fundação Ayrton Senna e IAS. Inicialmente, foram selecionados todos os trabalhos em que tais descritores estavam presentes em pelo menos em um dos itens a seguir: título, resumo ou palavras-chave.

Nessa coleta, realizada entre os dias 13 e 25 de março de 2016, foram examinados os bancos de teses e dissertações online da Coordenação de Aperfeiçoamento de Pessoal de Nível Superior (Capes) e os de todas as universidades estaduais e federais do Brasil. Também foram buscados trabalhos acadêmicos nos repositórios e portais de periódicos dessas instituições. Dados os limites da pesquisa, optou-se por não incluir no arcabouço da pesquisa as publicações em formato livro.

Após esse levantamento foram encontrados 184 estudos, dos quais sete teses, 29 dissertações, 64 artigos, três trabalhos de conclusão de curso (TCC), uma monografia e 80 comunicações apresentadas em seminários e congressos científicos. Na primeira triagem foram excluídas as comunicações, os TCCs e a monografia. Optou-se por trabalhos originários de pós-graduandos e professores doutores, tanto pela pressuposta maior complexidade dos estudos quanto pelos limites da pesquisa.

Quanto às teses e dissertações, após a coleta observou-se que mesmo constando os descritores no título, resumo ou palavras-chave, três dissertações e uma tese não tinham o IAS como foco da discussão. Após tais exclusões, resultaram seis teses, 24 dissertações e 34 artigos, que compõem o escopo da pesquisa.

Neste artigo são apresentadas, de forma resumida, as principais análises e conclusões da pesquisa, com indicação de questões sobre o IAS que merecem novos estudos para aprofundamento e melhor compreensão do papel deste Instituto no contexto das parcerias público-privadas na educação pública.

O artigo está dividido em três tópicos, no primeiro há breve apresentação do IAS, de forma que o leitor possa conhecer os objetivos, 
a estrutura e os projetos e programas implementados pelo Instituto. Em seguida, são apresentados e analisados os achados da pesquisa em diálogo com a literatura sobre o tema, com indicação das principais características da produção acadêmica estudada. Nas considerações finais faz-se uma síntese interpretativa das análises e são apresentados alguns desafios aos pesquisadores que pretendem contribuir com a compreensão da atuação do IAS na educação pública.

\section{O Instituto Ayrton Senna}

O Instituto Ayrton Senna foi fundado em 1994, a partir da iniciativa da família Senna após a morte do piloto de Fórmula 1. O IAS tem por meta "levar educação de qualidade para as redes públicas de ensino no Brasil. Atua em parceria com gestores públicos, educadores, pesquisadores e outras organizações para construir soluções concretas para os problemas da educação básica" (INSTITUTO AYRTON SENNA, 2016). Desde então vem criando programas educacionais "que se traduzem em políticas e práticas flexíveis que se adaptam a diversos contextos e efetivamente impactam a aprendizagem dos estudantes em grande escala" (INSTITUTO AYRTON SENNA, 2016). Juridicamente ele é definido como uma organização social, mas com razão social de instituto. Faz parte de uma gama de iniciativas privadas que emergiram já na primeira metade da década de 1990 e a partir de circunstâncias históricas favoráveis tiveram cada vez mais espaço nas políticas públicas voltadas à educação.

Segundo os relatórios anuais do Instituto, entre 1994 e 2010 seus programas e projetos atingiram 1.372 municípios brasileiros em 25 estados e o Distrito Federal. Esse número caiu entre 2011-2012 para 1.300 e teve redução contínua nos anos seguintes, chegando a $700 \mathrm{mu}$ nicípios atendidos em 2014. Por meio da Figura 1 pode-se observar que a presença do IAS em 2010 - ano em que teve parceria com o maior número de municípios - concentrava-se nas Regiões Norte e Nordeste do Brasil. Dos municípios da Região Nordeste, segundo o Instituto, pouco 
mais da metade participou de parcerias com o IAS. Na Região Norte, 43\% dos municípios participaram (INSTITUTO AYRTON SENNA, 2011). Os relatórios subsequentes, de 2011 a 2014, não apresentaram informação sobre a abrangência dos programas por região do Brasil.

Figura 1 - Abrangência dos programas do Instituto Ayrton Senna em 2010 $\underset{\text { POR REGIAOO }}{\text { Atendimento e abrangência }}$

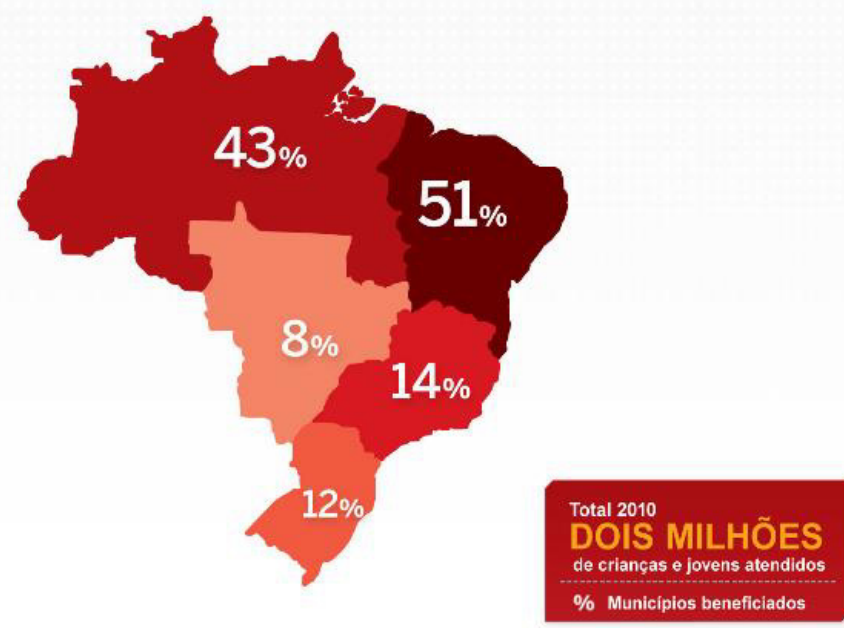

Fonte: INSTITUTO AYRTON SENNA (2011, p. 1).

Seus programas são apresentados como soluções para os problemas educacionais das séries iniciais do Ensino fundamental I (Acelera Brasil de 1997 e Se Liga de 2001), mas também para o Ensino fundamental II (Fórmula da Vitória de 2009 e Solução Educacional para o Ensino Médio de 2013).

A gama de estudos sobre o IAS permite atentar para a dimensão tomada pelos programas desta Instituição, ao longo de mais de vinte anos, de parcerias com secretarias de educação. Essa presença do IAS nas secretarias municipais e estaduais de educação influenciou, em alguma medida, 
a forma de pensar e fazer educação nesses entes federados e mobilizou a comunidade acadêmica a investigar como e em que medida isso aconteceu.

\section{A produção acadêmica sobre o Instituto Ayrton Senna: características e contribuições}

Grande parte da produção encontrada sobre o IAS está vinculada a um projeto nacional de pesquisa interinstitucional sob coordenação das professoras Vera Maria Vidal Peroni e Theresa Maria de Freitas Adrião, da Universidade Federal do Rio Grande do Sul (UFRGS) e da Universidade Estadual de Campinas (Unicamp), respectivamente. Conforme os dados da Tabela 1, dos 64 trabalhos encontrados, 54\% são provenientes de autores que participam dessa pesquisa. Para se chegar a essa constatação observou-se a lista de integrantes do grupo, conforme o relatório de pesquisa (ADRIÃO; PERONI, 2011).

Tabela 1 - Pesquisas interinstitucionais e não interinstitucionais sobre o Instituto Ayrton Senna

\begin{tabular}{|lll|}
\hline Tipo & Interinstitucional & Não interinstitucional \\
\hline Tese & 4 & 2 \\
\hline Dissertação & 10 & 14 \\
\hline Artigo & 21 & 13 \\
\hline Total & 35 & 29 \\
\hline
\end{tabular}

Fonte: o autor com base em dados da pesquisa (2016).

A análise das produções acadêmicas foi organizada por teses, dissertações e artigos e, a partir da leitura dos trabalhos, foi dividida por temas, são eles: contextualização do IAS pelos autores das pesquisas; precarização do trabalho docente; consenso passivo dos docentes e diretores; critérios de cientificidade.

Em relação à avaliação dos autores sobre as parcerias com o IAS, das 64 pesquisas apenas seis consideraram positivas as ações do 
Instituto (LEONÍDIO, 2010; PORTO, 2011; CALVO, 2003; HEREDERO, 2014; OLIVEIRA, 2002 e ELLIOT; SILVA; SILVA, 2007) na medida em que trouxeram bons resultados no que se refere à melhoria de índices educacionais como taxa de evasão, de repetência e de distorção idade/ série. Destas, quatro destacaram a importância do trabalho do IAS em relação aos aspectos cognitivos e emocionais para a aprendizagem dos alunos (CALVO, 2003, ELLIOT; SILVA; SILVA, 2007; HEREDERO, 2014 e OLIVEIRA, 2002). Estas pesquisas indicaram que a melhoria da qualidade educacional residiria no maior empenho dos alunos e dos profissionais da Educação e na valorização de aspectos cognitivos e emocionais como fundamentais ao desempenho escolar.

A maior parte considerou as parcerias como negativas porque foram inseridos valores mercadológicos na escola pública e o diretor foi transformado em gerente-gestor, sendo considerado o principal responsável pelos resultados educacionais da escola.

Alguns autores (BOLSON, 2011; SCHINEIDER, 2009) indicaram que os profissionais da Educação, principalmente os professores e gestores, aderiram ao controle sistemático do cotidiano escolar, mesmo com prejuízo ao trabalho pedagógico houve adesão aos parâmetros de qualidade baseados nas premissas do IAS e a consolidação de um consenso passivo tanto dos professores quanto das equipes gestoras, responsáveis pelas decisões na esfera educacional. Fato que mostra a força dessa organização social não estatal no processo de regulação da educação pública, que se submete ao conceito e à retórica de modernização dos sistemas de ensino tangenciada pelo discurso de pedagogismo pragmático e tecnocrático. A busca pelo consenso passivo apresentada pelos autores dos trabalhos analisados pode ser entendida como um sinal de que as ações não se legitimam por si, mas precisam de reconhecimento, o que é alcançado de diversas formas. Isso indica que a busca pela hegemonia do poder não se restringe ao núcleo do Estado, mas se encontra também na sociedade civil. A ideologia se reproduz por meio de intelectuais orgânicos das frações de classes em disputa por terreno político que reproduzindo hábitos, costumes e opiniões, influenciarão a formação de consciência (GRAMSCI, 2000). 
De acordo com a maioria dos trabalhos analisados, a participação, a gestão e a autonomia figuram nos materiais e nos discursos do IAS mas não têm o mesmo sentido daqueles preconizados na Constituição Federal de 1998 e na Lei de Diretrizes e Bases da Educação (LDB/1996), isto é, uma gestão escolar pautada na participação da comunidade escolar e local nas instâncias de elaboração e decisão do projeto político-pedagógico.

Uma das transformações mais identificadas, principalmente nas dissertações e teses (ALBUQUERQUE, 2010; BOLSON, 2011; DANTAS, 2011; PIRES, 2009; ROCHA, 2008; SCHINEIDER, 2009), foi a mudança na escolha dos diretores a partir das parcerias do Instituto com os municípios. A manutenção na função foi condicionada ao desempenho do diretor, e este à melhoria dos índices como evasão e taxa de repetência. Chama a atenção o fato de o termo de adesão à parceria com o IAS ter como um de seus itens a obrigatoriedade de os municípios selecionarem seus diretores de forma meritocrática, desse modo, a escolha dos diretores por meio de eleição pela comunidade ou pelo Conselho de Escola não poderia ocorrer nos entes federados que assinaram parceria com o IAS.

Em meio às avaliações críticas, alguns autores (DIAS, 2009; ROCHA, 2008; SILVA FILHO, 2014). Destacaram como positiva a sistematização dos dados sobre o desenvolvimento dos programas, como a frequência dos alunos e professores, notas e relatórios de atividades diárias, o que permitiu a racionalização das ações que, a partir de então, seriam direcionadas para objetivos alcançáveis em prazos relativamente curtos. Entretanto, a maioria concluiu que houve falta de transparência nas parcerias e mudanças nas legislações municipais exigidas pelo IAS. Ressaltaram ainda que as fronteiras entre o público e o privado foram redefinidas diante de discursos e ações estreitamente inspirados pelo neoliberalismo, que encontrou na "nova socialdemocracia" os meios políticos para a descentralização da realização de serviços antes tidos como de responsabilidade do Estado.

Encontraram-se construções argumentativas (ALBUQUERQUE, 2010; DANTAS, 2011; D’ÁVILA; FERNANDES, 2015; OLIVEIRA, 2012; GONZALEZ; BERNARDO, 2013; SOARES, 2010; LUMMERTZ, 2008; 
MICHEL, 2010; PINHEIRO, 2012; SILVEIRA, 2007) que ligaram os reformadores do Estado brasileiro a partir de 1995 (marco da maioria das pesquisas por conta do PDRAE) ao ideário neoliberal e/ou à terceira via. As dissertações e teses de autores que integraram a pesquisa interinstitucional aproximaram-se quanto à identificação desse panorama em que se desenvolveu o objeto de estudo.

Atentando-se para as 64 produções acadêmicas, grande parte considerou que a reforma do aparelho do Estado, a partir de 1995, foi influenciada por concepções de cunho neoliberal e da terceira via, mas a descentralização dos serviços sociais e as políticas públicas correspondentes foram baseadas especialmente nas premissas da terceira via; o Estado continuou financiando e fiscalizando a qualidade desses serviços, mas deixou parcialmente de executá-los, os repassando para as entidades privadas que comporiam o chamado terceiro setor. Essa constatação foi mais recorrente nas pesquisas cujos autores integraram a pesquisa interinstitucional.

As orientações dos órgãos internacionais, o discurso neoliberal e da terceira via, as políticas públicas durante a década de 1990, principalmente o PDRAE de 1995, seriam constituintes de um movimento ofensivo que visaria à expansão do lucro e à formação do consenso das classes hegemônicas, cujas premissas são baseadas nos valores de eficiência, eficácia e resultados, atingidos com baixo custo de execução.

Peroni e Silva (2013) pesquisaram as bases teóricas das ações do IAS, na medida em que buscaram a relação entre as orientações de organismos multilaterais, como a Organização das Nações Unidas para a Educação, a Ciência e a Cultura (Unesco) e o Banco Mundial (BM), com os princípios que norteiam os programas do IAS, obtidos por intermédio de documentos de divulgação e materiais de apoio. A convergência de interesses entre as empresas que apoiam esses projetos, os organismos internacionais e as entidades de um quase mercado visam à difusão de um novo perfil de sociabilidade baseado no ethos empresarial em torno do sistema do capital. Deriva dessa constatação a importância dos partidos políticos, movimentos sociais e das escolas, como elaboradores e (re) produtores de novas filosofias, as quais, indistinguíveis da política, são pedagógicas à medida que, para 
Gramsci (1999, p. 101), “a relação entre filosofia superior e senso comum é assegurada pela política”. A construção de um novo bloco histórico que envolva a conquista da hegemonia é fundamental para que a ascensão da classe trabalhadora à sociedade política signifique também sua hegemonia nos campos econômico, político e ideológico. A escolha de uma concepção de mundo, além de ser um fato político, é necessária para que as ações correspondam a elas, e para que assim haja sistematização das "próprias intuições do mundo e da vida" (GRAMSCI, 1999, p. 96).

O neoliberalismo e a terceira via, nessa leitura, são dois aparatos culturais-pedagógicos (NEVES, 2005) que buscam redefinir as relações entre as classes sociais. Isso não foi decorrente somente do fato de o projeto das classes hegemônicas assumir o aparato estatal, mas da fluidez da sociedade civil ser permeada pela aculturação voltada à conciliação de classes (NEVES, 2005).

Para Neves (2005), a terceira via como programa pedagógico-prático foi fundamental para desvincular o mercado da sociedade civil, pelo menos nos discursos. A sociedade civil seria fragmentada e setorializada num emaranhado de corporações que se relacionam com o Estado, nesse movimento, aos aparelhos privados de hegemonia caberia somente o associativismo empresarial (NEVES, 2005).

As ações do IAS inibiram a participação coletiva democrática na reelaboração constante dos projetos político-pedagógicos a partir da dinâmica escolar, ao centralizarem os problemas educacionais e os meios para resolvê-los na figura do diretor escolar e dos integrantes das organizações sem fins lucrativos, cujo campo de ação é voltado à educação pública.

A centralização dos processos e a consequente falta de autonomia dos profissionais da Educação levou alguns pesquisadores (OLIVEIRA, 2004; AMARAL, 2014; GUTIERRES, 2010; MILÉO, 2013; SOUSA, 2013) a identificarem a precarização do trabalho desses profissionais, caracterizada também pelo caráter temporário dos contratos e baixas remunerações. As noções rígidas de controle e sistematização do processo educativo do IAS interferem nas aulas e deslegitimam o saber do professor. A centralização tornou a rotina escolar desfavorável à formação para a 
cidadania, gerando frustração e stress como consequências da intensificação do trabalho. Um aspecto dessa condição de trabalho é a cobrança pelo engajamento individual às metas em detrimento do trabalho coletivo, busca incessante por objetivos e metas estabelecidas externamente que favoreceu a intensificação do trabalho dos professores, tornando-o "alienado" na medida em que há separação entre planejadores (IAS e secretarias de Educação) e executores (professores, alunos, diretores e coordenadores) e controlado pela reorganização dos organogramas da gestão municipal e definição de metas e tarefas para cada profissional.

As atuações do IAS agravaram o quadro de precarização do trabalho e das formas de contratação, intensificaram as atividades docentes ao estabelecerem metas e resultados a serem cumpridos independentemente das condições para sua realização, muitas vezes inadequadas. Entende-se que esse modelo de atuação está alinhado com o que a maioria dos autores dos trabalhos situaram como um modelo racional burocrático, que busca o empresariamento da educação pública no desenvolvimento de uma cultura da produtividade e na cobrança de resultados e metas.

De acordo com os autores dos trabalhos analisados, o contexto dessas ações é de precarização do ensino público, com corte de recursos, parcerias público-privadas que desconsideram a realização da gestão democrática, introdução de valores do mercado nas escolas, como a meritocracia, a competitividade entre as escolas e entre os alunos, e inserção de discursos neoliberais minimizando o efeito negativo da falta de recursos sobre a educação pública. As relações de emprego instáveis configuradas no contexto da desregulamentação da legislação trabalhista não devem ser confundidas com processos de trabalho precários (OLIVEIRA, 2004). Apesar de serem fenômenos covalentes, a flexibilização dos contratos permite a precariedade no trabalho docente e o grande número de professores rotativos afeta diretamente as condições de trabalho nas escolas que terão equipes instáveis, prejudicando o processo pedagógico.

A garantia de recursos materiais, infraestrutura e segurança na escola, assim como de apoio didático-pedagógico aos professores são fundamentais para que a escola possa ter êxito na aprendizagem dos alunos. 
Essas condições de trabalho não são somente decorrentes das parcerias dos municípios com o IAS, pois se referem à escassez de políticas públicas que propiciem melhoria na qualidade de ensino e valorização do trabalho docente. $\mathrm{O}$ advento dos contratos temporários nas redes públicas de ensino foi agravado pela mudança na forma de contratação dos diretores, que passaram a ter empregos instáveis mediante a relação entre sua manutenção no emprego e o desempenho das escolas nos índices educacionais.

Os trabalhos analisados indicam também que o IAS e sua relação com redes públicas de ensino estão inseridos no contexto de transformação do Estado brasileiro com diretrizes neoliberais, como a privatização e a terceirização. A confluência entre o neoliberalismo e a terceira via na crítica ao Estado e na necessidade da descentralização dos serviços sociais permitiu que políticas típicas de ambos os aparatos culturais-pedagógicos fossem implementadas no Brasil. Assim, de acordo com as pesquisas do grupo interinstitucional, se ocorreu a redefinição das fronteiras do público e do privado e o que fundamentou essas transformações foram as críticas ao Estado social feitas por intelectuais orgânicos, estreitamente inspirados pelo neoliberalismo e pela terceira via que encontraram na "nova socialdemocracia" os meios políticos para a descentralização dos serviços estatais (NEVES, 2005).

Em relação aos aspectos teórico-metodológicos dos trabalhos e os critérios de cientificidade, observou-se que os estudos do grupo de pesquisas interinstitucional utilizaram procedimentos metodológicos comuns, como entrevistas semiestruturadas, análises de documentos do IAS, documentos oficiais como as legislações e os termos de parceria com o Instituto. Foram estudos de caso que, por meio de um coletivo de pesquisadores, tiveram referenciais teóricos similares ou pelo menos aproximados. O critério de cientificidade dessas pesquisas assentou-se principalmente no cruzamento dos documentos do IAS e das falas dos entrevistados com os princípios, diretrizes e leis dos documentos oficiais.

As pesquisas que não participaram do grupo de estudo (JOÃO BATISTA ARAÚJO; OLIVEIRA, 2002; ELADIO SEBASTIÁN HEREDERO, 2014; IVAN PRICOLLI CALVO, 2003; AMARAL, BERTAGNA, 2015; 
GUTIERRES, 2010), mas encontraram diversas contradições nas atuações do Instituto, tiveram critérios de cientificidade variados, como, por exemplo, a análise de discursos identificados nos materiais de aprendizagem e documentos adquiridos no site do Instituto, agenciadores de subjetividade, conceitos que adquirem status de verdade e direcionam as ações dos indivíduos. Nessas pesquisas, as obras de Michel Foucault foram fundamentais para a metodologia e a análise.

Por outro lado, os estudos que indicaram avanços dos indicadores educacionais a partir dessas parcerias cruzaram dados estatísticos e índices educacionais anteriores e posteriores às parcerias. A validade situou-se também nos métodos de comparação e em ferramentas, que não foram explicitadas nos artigos analisados. Para legitimar as ações, os referidos autores precisaram também situar as propostas de atuação na educação pública a partir de legislações já existentes e, para isso, reproduziram as orientações de autonomia, participação, gestão democrática etc., mas as ressignificando nos discursos para que elas adquirissem um caráter apenas formal.

Em suma, entende-se que a bibliografia estudada sobre pesquisas referentes ao Instituto Ayrton Senna indica que em nenhuma das parcerias citadas os índices de evasão escolar, reprovação e distorção idade/ série propostos pelo IAS foram alcançados e, independentemente dos resultados finais, dificilmente haveria a possibilidade de medir exatamente a influência do IAS na melhoria desses índices, já que antes das parcerias e no decorrer delas outros projetos foram desenvolvidos na educação municipal. As pesquisas analisadas também indicaram que o IAS difundiu um projeto empresarial vinculado à autorresponsabilização do indivíduo pelas suas mazelas sociais. A grande matriz dessa práxis é o avanço recente do capital sobre a questão social, que se desenvolveu com a ajuda do pensamento neoliberal e da terceira via. A classe dominante busca lucrar apoiada na força publicitária desses projetos, revestidos de filantropia e responsabilidade social. 


\section{Considerações finais}

A análise de trabalhos acadêmicos sobre o IAS sugere que ocorreu uma colonização do setor público pelo privado, levando para este a lógica privada não democrática, que busca somente resultados estatísticos ligados a valores empresariais como eficiência, meritocracia e melhoria de desempenho. Tal colonização desenvolveu-se a partir da descentralização do angariamento e gerenciamento de recursos financeiros das unidades de ensino, que possibilitou a abertura para projetos educacionais e financiamento pela iniciativa privada, ações estas mediadas por iniciativas privadas sem fins lucrativos, a partir do entrelaçamento de fronteiras entre o setor público estatal burocrático e essas organizações da sociedade civil. A referida colonização também pode ser entendida como a aculturação mercantil da educação pública, que se voltou às necessidades da economia a partir de intervenções da iniciativa privada no conteúdo curricular, dando novos sentidos à função da escolarização por meio dessas intervenções. Esse fenômeno pôde ser identificado pelos autores na introdução de códigos empresariais na educação como a meritocracia, a competitividade e a premiação, mudanças nas legislações municipais como exigência do IAS, a redução dos conteúdos às matérias de Português e Matemática, a ênfase nos resultados expressos em dados estatísticos, em índices educacionais e o discurso crítico ao Estado, que seria incompetente para gerir os serviços públicos.

O material estudado mostrou um rico leque de informações e análises. Acredita-se que as principais conclusões e características foram averiguadas, mas algumas questões não foram exploradas, tais como: as concepções de Estado e de educação presentes nas propostas do IAS conseguiram hegemonia entre educadores e estudantes das escolas onde os projetos foram desenvolvidos? Quais as formas de resistência a esse processo, no qual professores e alunos são frequentemente responsabilizados pelas consequências de políticas públicas equivocadas ou inexistentes? Assim, novos estudos sobre o IAS poderiam abarcar questões pouco ou ainda não estudadas, o que contribuiria para um conhecimento mais amplo sobre a presença deste Instituto na educação pública básica brasileira. 


\section{Referências}

ADRIÃO, T.; PERONI, V. Análise das consequências de parcerias firmadas entre municípios brasileiros e a Fundação Ayrton Senna para a oferta educacional. Relatório de Pesquisa ao CNPq. 2011. Disponível em: <http://www.ufrgs.br/faced/peroni/docs/INSTITUTO\%20 AYRTON\%20SENNA\%20RELATORIO.pdf >. Acesso em: 12 jun. 2016.

BRASIL. Ministério da Administração Federal e Reforma do estado. Plano diretor da reforma do aparelho do Estado. Brasília, DF, 1995.

CANDAU, V. M. Reformas educacionais hoje na América Latina. In: MORREIRA, A. F. B. (Org.). Currículo: políticas e práticas. Campinas: Papirus, 2002. p. 29-42.

GRAMSCI, A. Cadernos do cárcere. Rio de Janeiro: Civilização Brasileira, 1999. v. 1. Trad. Carlos Nelson Coutinho, colab. Luiz Sergio Henriques, Marco Aurélio Nogueira.

GRAMSCI, A. Cadernos do cárcere. Rio de Janeiro: Civilização Brasileira, 2000. v. 3. Trad. Carlos Nelson Coutinho.

FERREIRA, L. S. A pesquisa educacional no Brasil: tendências e perspectivas. Contrapontos, Itajaí, v. 9, n. 1, p. 43-54, jan./abr. 2009.

FRANÇA, C. L.; MATTA, K. W.; ALVES, E. D. Psicologia e educação a distância: uma revisão bibliográfica. Psicologia: Ciência \& Profissão, Brasília, v. 32, n. 1, p. 4-15, 2012.

OLIVEIRA, D. A. A reestruturação do trabalho docente: precarização e flexibilização. Educação \& Sociedade, Campinas, v. 25, n. 89, p. 1127-1144, set./dez. 2004.

NEVES, L. M. W. (Org.). A nova pedagogia da hegemonia: estratégias do capital para educar o consenso. São Paulo: Xamã, 2005.

PERONI, V. M. V.; ADRIÃO, T. A relação público/privado e a gestão da educação em tempos de redefinição do papel do Estado. In: ADRIÃO, T.; PERONI, V. Público e privado na educação: novos elementos para o debate. São Paulo: Xamã, 2008. p. 111-127. 
VOSGERAU, D. S. R.; ROMANOWSKI, J. P. Estudos de revisão: implicações conceituais e metodológicas. Revista Diálogo Educacional, Curitiba, v. 14, n. 41, p. 165-189, jan./abr. 2014.

Recebido: 16/06/2018

Received: 06/16/2018

Aprovado: 16/09/2018 Approved: 09/16/2018 


\section{Anexo}

\section{Teses consultadas}

ALVAREZ, A. M. T. A infografia na educação: contribuições para o pensar crítico e criativo. Tese (Doutorado em Educação) - Programa de Pós-Graduação em Educação, Universidade de São Paulo, São Paulo, 2012.

AMARAL, M. C. E. Relações Público privado na educação de Mato Grosso. 2014. Tese (Doutorado) - Faculdade de Educação, Universidade Estadual de Campinas, Campinas, 2014.

COMERLATTO, L. P. A gestão da educação no contexto da sociedade capitalista: A parceria público-privado. Tese (Doutorado) - Programa de Pós-Graduação em Educação, Faculdade de Educação, Universidade Federal do Rio Grande do Sul, Porto Alegre, 2013.

GUTIERREZ, D. V. G. A municipalização do ensino no município de Altamira e suas implicações para a democratização educacional. Tese (Doutorado) - Programa de Pós-Graduação em Educação, Faculdade de Educação, Universidade Federal do Rio Grande do Sul, Porto Alegre, 2010.

MILÉO, I. S. O. Sistemas municipais de ensino e o IAS na Amazônia paraense. Tese (Doutorado) - Universidade Católica de São Paulo, São Paulo, 2013.

POJO, O. C. A parceria público-privado do Instituto Ayrton Senna e a prefeitura municipal de Benevides-PA: entre os desafios (pro)postos e os limites da realidade. Tese (Doutorado) - Programa de Pós-Graduação em Educação, Universidade Federal do Pará, Belém, 2014.

SOUZA, W. L. O programa gestão Nota 10 do Instituto Ayrton Senna e a educação em Santarém-PA. 2013. Tese (Doutorado) - Programa de Pós-Graduação em Educação, Instituto de Ciências da Educação, Universidade Federal do Pará, Belém, 2013. 


\section{Dissertações consultadas}

ALBUQUERQUE, E. M. A implementação do Programa Gestão Nota 10 no Sistema Municipal de Educação de Mossoró/RN (2005-2009). Dissertação (Mestrado) Universidade Federal do Rio Grande do Norte, Natal, 2010.

BASÍliO, L. F. Conversação eletrônica em um grupo de discussão via internet. Dissertação (Mestrado) — Universidade de São Paulo, São Paulo, 2007.

BOLSON, H. S. P. A certificação ocupacional de dirigentes escolares da rede municipal de ensino de Campo Grande-MS: implicações para a gestão escolar (2001-2004). Dissertação (Mestrado) — Universidade Católica Dom Bosco, Campo Grande, 2011. CHAVES, D. S. P. Instituto Ayrton Senna: ressignificando a função social da escola pública no município do Rio de Janeiro através do "Programa Acelera Brasil". Dissertação (Mestrado) - Universidade Estadual do Rio de Janeiro, Rio de Janeiro, 2012.

DANTAS, L. C. L. Política de gestão escolar da rede municipal de ensino de Campo Grande-MS: implicações da parceria público privada (2005-2008). Dissertação (Mestrado em Educação) — Universidade Católica Dom Bosco, Campo Grande, 2013.

DIAS, P. S. F. Mercado e educação: a política do Instituto Ayrton Senna no Município de Cabedelo/PB. Dissertação (Mestrado) - Universidade Federal da Paraíba, João Pessoa, 2009.

LÉLIS, U. A. Políticas e práticas do "Terceiro Setor" na educação brasileira no contexto de reconfiguração do Estado. Dissertação (Mestrado) - Universidade Federal de Uberlândia, Uberlândia, 2007.

LEONÍDIO, L. F. S. Projetos e ações sociais de esporte e lazer: A intervenção do projeto Santo Amaro e sua dinâmica interinstitucional de parceria. Dissertação (Mestrado) - Universidade Federal do Pernambuco, Recife, 2010.

LUMMERTZ, J. S. A parceria público-privada na educação: implicações para a gestão da escola. Dissertação (Mestrado em Educação) - Programa de Pós-Graduação em Educação, Universidade Federal do Rio Grande do Sul, Porto Alegre, 2008. 
MICHEL, J. C. M. A ação do Instituto Ayrton Senna na gestão das políticas educacionais: alianças sociais e legitimação do gerencialismo na educação. Dissertação (Mestrado) — Universidade do Vale do Itajaí, Itajaí, 2010.

MILÉO, I. S. O. Poder Local e a gestão municipal no contexto de Altamira-PA. Dissertação (Mestrado) — Universidade Federal do Pará, Belém, 2007.

OLIVEIRA, I. P. O "terceiro setor" e a execução de programas educacionais: a parceria entre o Governo do Maranhão e o Instituto Ayrton Senna no Projeto Gestão Nota 10. Dissertação (Mestrado) — Universidade Federal do Maranhão, São Luís, 2013.

PINHEIRO, D. O programa Gestão Nota 10 do IAS: aproximações coma gestão da qualidade total (CGT) e o movimento das escolas eficazes. Dissertação (Mestrado) - Universidade Estadual de São Paulo, São Paulo, 2012.

PIRES, D. O. A configuração jurídica e normativa da relação público-privada no Brasil na promoção do direito à educação. Dissertação (Mestrado) - Universidade Federal do Rio Grande do Sul, Porto Alegre, 2009.

PORTO, M. I. A. G. Instituto Ayrton Senna: quebra de paradigma na gestão pública de Caruaru-PE. Dissertação (Mestrado) — Universidade Federal de Pernambuco, Recife, 2011.

QUEIROZ, R. S. N. O papel do Terceiro Setor nas políticas públicas a partir dos anos 1990 no Brasil: análise da parceria Instituto Ayrton Senna e SEDUC-TO na oferta dos programas Se Liga e Acelera Brasil (2004-2009). Dissertação (Mestrado) Universidade Federal de Goiás, Goiânia, 2010.

ROCHA, A. B. B. A parceria entre o público e o privado na educação: implicações do Programa Escola Campeã para a gestão escolar. Dissertação (Mestrado em Educação) - Universidade Católica Dom Bosco, Campo Grande, 2008.

SALDANHA, A. M. S. "Terceiro Setor": um estudo sobre o projeto Santo Amaro (Recife-PE). Dissertação (Mestrado) — Universidade Federal de Pernambuco, Recife, 2010. 
SILVA FILHO, A. A. S. Parceria público/privada em educação: análise do projeto Alfabetizar Com Sucesso/ Programa Circuito Campeão no município de Surubim/PE. Dissertação (Mestrado) — Universidade Federal do Pernambuco, Recife, 2014.

SILVEIRA, J. Desenvolvimento humano, responsabilidade social e educação no capitalismo: investigando o programa "Educação Pelo Esporte" do Instituto Ayrton Senna. Dissertação (Mestrado) - Universidade Federal de Santa Catarina, Florianópolis, 2007.

SOARES, L. B. A ação do Instituto Ayrton Senna na Rede Municipal de Educação de Joinville/SC (2001-2008): subordinação da escola pública a princípios e métodos da gestão empresarial. Dissertação (Mestrado) — Universidade Federal de Santa Catarina, Florianópolis, 2010.

SCHINEIDER, S. O Projeto piloto de alfabetização do Rio Grande do Sul: um olhar de estranhamento sobre seus materiais didáticos. Dissertação (Mestrado) Universidade Federal do Rio Grande do Sul, Porto Alegre, 2009.

VASCONCELOS, M. Projeto Criança Feliz: Um estudo de caso da aplicação da Cosmovisão Calvinista na Ação Social. Dissertação (Mestrado em Ciências da Religião) — Universidade Presbiteriana Mackenzie, São Paulo, 2014.

\section{Artigos consultados}

ADRIÃO, T.; PERONI, V. M. V. Consequências da Atuação do Instituto Ayrton Senna para a Gestão da Educação Pública: observações sobre 10 estudos de caso. Práxis Educativa, Ponta Grossa, v. 6, n. 1, p. 45-53, jan./jun. 2011.

ALMEIDA, A. P.; JUNQUILHO, G. S.; SOUZA, S. P. Programa Escola Campeã na Gestão Escolar: o Hibridismo entre a Racionalidade Burocrática e uma "Anarquia Organizada". Revista Gestão e tecnologia, Pedro Leopoldo, v. 8, n. 2, p. 1-19, jul./ago. 2008. 
AMARAL, M. C. E.; BERTAGNA, R. H. A opacidade nas relações estabelecidas entre o setor privado e a educação pública estadual de Mato Grosso. Educação: teoria e prática, Rio Claro, v. 25, n. 50, p. 504-519, 2015.

CAETANO, M. R.; CHAVES, D. S. P. A gestão pedagógica da escola e as concepções de um programa do Instituto Ayrton Senna: de qual pedagógico estamos falando? Colóquio: Revista do Desenvolvimento Regional, Taquara, v. 11, n. 1, jan./ jun. 2014.

CALVO, I. P. Avaliação de Desempenho do "Programa Acelera": um estudo de caso. Revista Iberoamericana de Educación, 10 fev. 2003. Disponível em: <http:// rieoei.org/rie_contenedor.php?numero=inv_edu9\&titulo=Instituto\%2520Ayrt on\%2520Senna.\%2520Avalia\%25E7ao\%2520de\%2520desempenho\%2520do>. Acesso em: 7 jun. 2016.

COSTA, M. O. Parceria, Participação e Trabalho Voluntário na Educação. Germinal: Marxismo e Educação em Debate, Salvador, v. 6, n. 1, p. 98-108, jun. 2014.

COSTA, M. O. Terceiro Setor, teoria das organizações e qualidade na educação. Perspectiva, Florianópolis, v. 30, n. 3, 1011-1044, set./dez. 2012.

COSTA, M. O.; GENTIL, H. S.; LIMA, F. S. F.; COSTA, K. A. Implicações da parceria público-privada para a gestão e autonomia da educação no município de Cáceres-MT. Revista da Faculdade de Educação, ano 10, n. 18, jul./dez. 2012.

D’AVILA, J. L.; FERNANDES, C. M. Políticas Esportivas do Terceiro Setor no Estado de Mato Grosso do Sul: uma análise do Projeto Córrego Bandeira. Motrivivência, v. 27, n. 44, p. 24-35, maio/2015.

ELLIOT, L. G.; SILVA, C. M. T.; SILVA, A. G. A Qualidade do Programa Escola Campeã: avaliação externa de gestão e eficiência. Revista Electrônica IberoAmericana Sobre Calidad, Eficacia y Cambio en Educación, v. 5, n. 2e, p. 100-115, 2007.

FERNANDES, M. D. E.; ALVES, A. G. R. Parcerias público-privado na esfera municipal: implicações para a gestão e oferta educacional. Práxis Educativa, Ponta Grossa, v. 9, n. 1, p. 69-90, jan./jun. 2014. 
GARCIA, T. O. G.; ADRIÃO, T. M. F.; ARELARO, L. R. G. O Programa Gestão Nota 10 do Instituto Ayrton Senna na rede municipal de ensino de São José do Rio Preto: Decorrências para a gestão educacional. Revista da faculdade de Educação, ano 10, n. 18, jul./dez. 2012.

GONZALEZ, W.; BERNARDO, E. A gestão democrática em espaços não formais de ensino. Série-Estudos, Campo Grande, n. 36, p. 63-76, jul./dez. 2013.

GUTIERRES, D. V. A municipalização do ensino e a democratização educacional no município de Altamira (PA). Educação em foco, ano 15, n. 20, p. 123-144, dez. 2012.

HEREDERO, E. S. Considerações sobre a fundamentação teórica que sustenta os programas de correção da defasagem escolar "Se liga" e "Acelera Brasil" do Instituto Ayrton Senna. 2014.

INSTITUTO AYRTON SENNA. Quem somos. São Paulo. Disponível em: <http:// www.institutoayrtonsenna.org.br/quem-somos/>. Acesso em: 7 jun. 2016.

INSTITUTO AYRTON SENNA. Relatório de resultados 2010. São Paulo, 2011.

MILÉO, I. S. O.; CHIZZOTTI, A. Da Escola Campeã ao Programa Rede Vencer: um olhar sobre SUAS repercussões na gestão e na organização curricular e pedagógica da educação municipal em Altamira-Pará. Educação e Fronteiras On-Line, Dourados, v. 2, n. 5, p. 63-78, maio/ago. 2012.

NASCIMENTO, C. G. Neoliberalismo, Estado e Terceiro Setor: uma análise do Programa "Se Liga Goiás”. Revista Urutágua, n. 23, jan./abr. 2011.

OLIVEIRA, A. G. A.; LUZ, L. X.; ANJOS, C. R.; SÁ, E. V. A Participação do Setor Privado na Gestão do Sistema Municipal de Educação em Teresina-PI: o caso do programa Gestão Nota 10 do Instituto Ayrton Senna. Jornal de Políticas Educacionais, n. 8, p. 74-81, jul./dez. 2010.

OLIVEIRA, I. P.; COUTINHO, A. F. O “Terceiro Setor” e a execução de programas educacionais: a parceria entre o Governo do Maranhão e o Instituto Airton Senna no Projeto Gestão Nota 10. Revista Educação e Emancipação, São Luís, v. 7, n. 1, jan./jun. 2014. 
OLIVEIRA, J. B. A. Correção do Fluxo Escolar: um balanço do Programa Acelera Brasil (1997-2000). Cadernos de Pesquisa, n. 116, p. 177-215, jul. 2002.

OLIVEIRA, R. T. C. O Programa Gestão Nota 10 no âmbito das parcerias entre governos municipais e o Instituto Ayrton Senna. Revista da Faculdade de Educação, ano 10, n. 18, jul./dez. 2012.

OLIVEIRA, R. T. C.; BOLSON, H. S. P.; DANTAS, L. C. L. Política de Gestão da Educação Municipal: implicações para a direção escolar. Série-Estudos, Campo Grande, n. 30, p. 325-338, jul./dez. 2010.

PERONI, V. M. V. Conexões entre o público e o privado no financiamento e gestão da escola pública. EccoS: Revista Científica, São Paulo, v. 8, n. 1, p. 111-132, jan./jun. 2006.

PERONI, Vera Maria Vidal; SILVA, Maria Vieira. Estado, Terceira Via, Terceiro Setor e o Instituto Ayrton Senna. In: ADRIÃO, Teresa; PERONI, Vera Maria Vidal (Org.). Gestão municipal da educação e as parcerias como Instituto Ayrton Senna. Goiânia: Funape; Recife: Anpae, 2013. p. 37-59.

PERONI, V. M. V. Reforma do Estado e Políticas Educacionais no Brasil. Revista Educação e Políticas em Debate, v. 1, n. 1, jan./jul. 2012.

PERONI, V. M. V.; AMARAL, J. C. S. R.; COMERLATTO, L. P.; COSTA, M. O.; SUSIN, M. O. K. Terceira Via, Terceiro Setor e a parceria IAS/sistemas de ensino público no Brasil. Políticas Educativas, Porto Alegre, v. 3, n. 2, p. 56-73, 2010.

PERONI, V. M. V.; CAETANO, M. R. Redefinições no papel do Estado: Terceira Via, novo desenvolvimentismo e as parcerias público-privadas na educação. Educ. Humanismo, v. 13, n. 20, p. 234-253, jun. 2011.

PERONI, V. M. V, LUMERTZ, J. S. A parceria público-privada entre o Instituto Ayrton Senna e a Rede Municipal de Ensino de Sapiranga. Revista da Faculdade de Educação, ano 10, n. 18, jul./dez. 2012.

PICCININI, C. L. O empresariamento da Educação Pública: o caso do Programa Acelera Brasil. Germinal: Marxismo e Educação em Debate, Salvador, v. 5, n. 1, p. 110-121, jun. 2013. 
PIRES, D. O.; PERONI, V. M. V. Terceira Via e Terceiro Setor: aspectos jurídicos e consequências para a política educacional brasileira. Políticas Educativas, Porto Alegre, v. 3, n. 2, p. 56-73, 2010.

RODRÍGUEZ, M. V.; FERNANDES, M. D. E.; ALVES, A. G. R.; SEVERINO, J. L. Formação e avaliação de diretores de escolas no âmbito da parceria entre municípios e o Instituto Ayrton Senna. Educere et Educare: Revista de Educação, v. 5, n. 10, 2. sem. 2010.

SANTOS, T. F. A. M. Parcerias público-privadas e gestão escolar pública. Revista Cocar, Belém, v. 7, n. 14, p. 66-72, ago./dez. 2013.

SILVEIRA, J. Responsabilidade Social, ONGs e Esporte: o caso do Instituto Ayrton Senna no Brasil. In: MATIELLO JÚNIOR, E.; CAPELA, P.; BREILH, J. Ensaios alternativos latino-americanos de educação física, esportes e saúde. Florianópolis: Copiart, 2009. 200p.

SOUZA, C. M.; CARNEIRO, W. Projeto Realfabetização no Município do Rio de Janeiro (2009-2010): análise da política pública, pelos docentes da $7^{a}$ Coordenadoria Regional de Educação (CRE) 1. Roteiro, Joaçaba, Edição Especial, p. 205-230, 2014. 